\title{
Mycorrhizal Fungi Enhance Resistance to Herbivores in Tomato Plants with Reduced Jasmonic Acid Production
}

\author{
Ludovico Formenti * (D) and Sergio Rasmann $\mathbb{D}$ \\ Institute of Biology, University of Neuchâtel, Rue Emile-Argand 11, 2000 Neuchâtel, Switzerland; \\ Sergio.rasmann@unine.ch \\ * Correspondence: Ludovico.formenti@unine.ch; Tel.: +41-32-718-2317
}

Received: 23 January 2019; Accepted: 6 March 2019; Published: 12 March 2019

check for updates

\begin{abstract}
Arbuscular mycorrhizal (AM) fungi favor plant growth by improving nutrient acquisition, but also by increasing their resistance against abiotic and biotic stressors, including herbivory. Mechanisms of AM fungal mediated increased resistance include a direct effect of AM fungi on plant vigor, but also a manipulation of the hormonal cascades, such as the systemic activation of jasmonic acid (JA) dependent defenses. However, how AM fungal inoculation and variation in the endogenous JA production interact to produce increased resistance against insect herbivores remains to be further elucidated. To address this question, three genotypes of Solanum lycopersicum L., a JA-biosynthesis deficient mutant, a JA over-accumulating mutant, and their wild-type were either inoculated with AM fungi or left un-inoculated. Plant growth-related traits and resistance against Spodoptera littoralis (Boisduval) caterpillars, a major crop pest, were measured. Overall, we found that deficiency in JA production reduced plant development and were the least resistant against S. littoralis. Moreover, AM fungi increased plant resistance against $S$. littoralis, but such beneficial effect was more pronounced in JA-deficient plant than on JA over-accumulating plants. These results highlight that AM fungi-driven increased plant resistance is negatively affected by the ability of plants to produce JA and that AM fungi complement JA-mediated endogenous plant defenses in this system.
\end{abstract}

Keywords: arbuscular mycorrhizal fungi; herbivores; plant-microbe-insect interaction; plant resistance; prosystemin; Rhizophagus irregularis

\section{Introduction}

Plants are the primary source of energy on Earth and are constantly under attack by higher trophic-level organisms such as herbivores and pathogens [1]. To cope with biotic attack, plants have evolved a plethora of defensive strategies, which range from nutrient allocation and overcompensation of damaged tissue to mechanical and chemical defenses [2-4]. The coordination of the plant defense responses to biotic attack is mediated by plant hormones [5], of which jasmonic acid (JA), salicylic acid (SA), and ethylene (ET) are the most crucial. Other phytohormones, such as abscissic acid (ABA), gibberellins, auxins, and cytokinins, however, are emerging as important defense regulators as well $[6,7]$. More specifically, plants' responses to leaf chewing herbivores are mainly mediated by JA and a related compound [8,9], which when activated, modify plants' physical and chemical phenotypes, in general resulting in increased resistance against the attacker. Moreover, upon damage, a plant may enter in a state of priming for more rapid and intense response to a subsequent stress [10]. Plant defense priming has been observed upon herbivore damage [11] and pathogen attack [12], but also in plants interaction with soil microorganisms, such as mycorrhizal fungi [13-15]. 
In terrestrial ecosystems, approximately $80 \%$ of the vascular plants can associate in roots endosphere with obligate biotrophes such as arbuscular mycorrhizal fungi (AM fungi), which colonize plant roots for acquisition of photosynthetic products in exchange of nitrogen, phosphorus, minerals, and water [16]. The benefits of plant-AM fungi association are not only restricted to enhancing soil nutrient uptake by the plant, but also by enhancing plant defenses against pathogens $[17,18]$ or herbivores $[19,20]$. A meta-analysis reporting the general effect of AM fungi on plant insect herbivore interaction has highlighted variation across insect feeding guilds and that AM-mediated increased resistance is particularly strong against generalist chewing insect herbivores [21], although results from different studies strongly vary, even reporting cases of increased plant susceptibility after AM fungi colonization [22].

The mechanisms for AM fungi-mediated that increase plant resistance against herbivores and pathogens include: (i) increased plant tolerance; (ii) modification of the physical and chemical plant phenotype $[19,23,24]$; and (iii) the priming of defenses $[13,25,26]$. First, AM fungi association indirectly increases plant tolerance by enhancing nutrient uptake. Tao et al. [27] showed an increased tolerance to defoliation across different milkweed (Asclepias) species when colonized by AM fungi. Second, AM fungi can stimulate plants to produce more toxins because more energy is available. Vannette et al. [28] observed increased cardenolide production in milkweeds when colonized by AM fungi, but this effect was highly species-specific. Third, AM fungal colonization can prime plant defenses during the mycorrhization process, which indeed requires the antagonistic activation of the SA and JA pathways $[17,29]$. Song et al. [14], showed that the AM fungus Funneliformis mossae (T.H.Nicolson \& Gerd.) C.Walker \& A.Schüßler primed JA-dependent defenses in tomatoes plant (i.e., JA-related gene expression was stronger after AM-fungal colonization) and reduced the performance of the generalist herbivore caterpillars Helicoverpa arimigera (Hubner).

To summarize, the protective effects of AM fungi vary depending on several factors such as plant and fungal genetic make-up, as well as herbivore type. This hypothesis is also based on the observations that AM fungi can sometimes diminish plant resistance while favoring growth [30], as well as the functionally distinct AM fungi that differentially induces resistance and defenses, including JA production [31]. Therefore, the interaction between fungal functional types and plant genotypic variation in defense would result in differential resistance against herbivores. In the present study, we addressed the interactive effects of JA production and AM fungi on plant growth and resistance against herbivores. We had two contrasting predictions: (1) AM fungal inoculation increases resistance only when the JA signaling pathway is functional. This prediction stands on the assumption that that AM-fungal colonization triggers plant defense priming. (2) The benefits of AM fungal inoculation are mainly visible on JA-impaired plants. This prediction rests of the assumption that AM-fungal effect on plant resistance is independent of JA priming and/or activation.

To test our predictions, we manipulated the JA phytohormonal pathway (JA-treatment) by using three tomato plant types: (1) a tomato mutant defenseless-1 (def-1) that is defective in the JA biosynthetic pathway [32] and used in several studies investigating the biotic and abiotic stress on plant resistance and development [33-36]. The tomato line def-1 is mutated downstream to JA production at a gene encoding for a JA precursor (12-OPDA). Therefore, while this line may be still responsive to JA, it shows a serious reduction of JA accumulation leading to a severe decrease of protein inhibitor II [37]. (2) A transgenic tomato line 35S::prosystemin (35S::PS) that constitutively overexpresses the plant peptide hormone prosystemin, which leads to the constitutive production of systemin (generally only released after wounding), is the subsequent induction of JA-related plant defense genes and JA accumulation $[38,39]$. Ultimately, this cascade of events is mainly followed by the upregulation of protein inhibitors and various defensive secondary metabolites, but it has been shown to also affect several additional hormonal and physiological processes in the plant [40]. (3) A wild-type (WT) tomato (cv. Castlemart) that is in the same genetic background and used to compare with the two mutant lines [41]. Overall, while these three plant types differ greatly in expression of defenses (see results), they are morphologically indistinguishable [42]. The use of these tomato lines is a well-established 
system for investigating JA-dependent plant defenses and to measure the direct effect of JA signaling in combination with other treatments [43]. To investigate the synergic effect of AM fungi and plant genotype on plant resistance against a generalist herbivore attack, tomato plants where infested with the Egyptian cotton leafworms Spodoptera littoralis (Lepidoptera: Noctuidae), which is a highly polyphagous nocturnal moth originating from North Africa and Mediterranean Basin and is considered a major pest of crop plants including tomato [44]. We expect that if the magnitude of the AM fungal effect on plant resistance was higher in JA-accumulating plants, it would indicate synergism between AM fungi and JA signaling pathway [14]. If the magnitude of the AM fungal effect on plant resistance was higher in JA signaling-impaired plants, it would indicate complementarity of the effects of AM fungi and JA signaling pathway.

\section{Materials and Methods}

\subsection{Plant Growth and Mycorrhizal Inoculation}

We measured the effect of JA production and AM inoculation on tomato plants' resistance against a generalist caterpillar feeding on six JA-by-AM fungi combination treatments. Seeds of all tomato plants were surface-sterilized with bleach solution ( $5 \%$ commercial bleach) and germinated on a culture media with $8 \%[w / v]$ agar, MS-agar (2g/L of Murashige and Skoog Basal Salt Mixture (Sigma-Aldrich, Saint Louis, MO, USA), and 0.25 g/L MES hydrate (Sigma-Aldrich, Saint Louis, MO 63103, USA)) on petri dishes. One week after germination, 36 seedlings of each genotype were transplanted in $1 \mathrm{~L}$ plastic pots filled with autoclaved soil mixture of medium-low P potting soil (Orbo-2, Schweizer AG, Lausanne; Switzerland) with perlite (3:1 v:v). Soil was autoclaved twice at $121^{\circ} \mathrm{C}$ for $20 \mathrm{~min}$ with a rest of $24 \mathrm{~h}$ between the cycles. No fertilizer was added to the soil during the experiment. Next the plants were assigned to one of two AM fungi treatments: the control without fungi (un-inoculated) or a mycorrhizal treatment (AM-inoculated) by directly inoculating 250 fungal spores in $1 \mathrm{~mL}$ water solution (Rhizophagus irregularis (Błaszk., Wubet, Renker \& Buscot) C.Walker \& A.Schüßler, Glomygel, Micovitro S.L., 18220 Albolote, Granada, Spain) near the roots, $1 \mathrm{~cm}$ deep into the soil. The control plants received the same amount of autoclaved spore solution. The same procedure was repeated again after one week of growth. Plants were then randomized on a greenhouse bench and allowed to grow for seven weeks at $25 / 18{ }^{\circ} \mathrm{C}, 14 \mathrm{~h}$ /day length and $55 \%$ relative humidity prior to insect infestation. We used 18 plants per three genotype (def- 1 , WT, 35S::prosystemin) per two AM fungal treatment (un-inoculated and AM-inoculated) resulting in 108 plants, of which 36 where left herbivore-free as control, and 72 where later infested with caterpillars for the resistance bioassay (see below).

\subsection{Plant Growth and Resistance Bioassay}

Eggs of S. littoralis were obtained from Syngenta, Stein, Switzerland and hatched at $18^{\circ} \mathrm{C}$. Next, 10 first instar, with a maximum 24-h old, larvae were placed on plants assigned to the herbivore treatment ( $n=12$ plants per genotype and per AM fungi treatment). Prior to insect infestation, all plants (including herbivore-free plants) were covered with a fine-mashed nylon net to prevent larval movement away from plants. After one week of herbivore infestation, larvae where collected and dried at $40{ }^{\circ} \mathrm{C}$ over four days. Larval survival on each plant was recorded and the dry biomass of larvae were measured and averaged for each plant. 
At the end of the herbivory assay, six functional traits in tomato plants were recorded: (1) plant size, measured as the distance between the stem bottom and the highest stretched canopy part; (2) plant aboveground biomass and (3) root biomass, both measured after seven days drying in an oven at $40{ }^{\circ} \mathrm{C}$; (4) chlorophyll content, measured three times per leaf and for three leaves per plant using a SPAD-502Plus chlorophyll meter (Konica Minolta Investment Ltd., Chiyoda, Tokyo, Japon), which informs about the chlorophyll concentration by measuring ultraviolet light refraction of chlorophyll; (5) specific leaf area (SLA), measured as the area of three leaf discs of $1 \mathrm{~cm}$ in diameter per plant divided by their dry biomass $\left(\mathrm{mm}^{2} \mathrm{mg}^{-1}\right)$; and (6) trichome density, recorded as the number of all type trichomes on the adaxial part of the middle section of the largest leaflet. Chlorophyll content, SLA, and trichome density were measured on the youngest fully expanded non-infested systemic leaves. We chose this set of functional traits in order to assess the effect of JA and AM fungi on plant performance. Besides the number of trichome density that could be directly linked to plant resistance against chewing herbivore insects [45] and SLA that can be considered as both a plant resistance trait (reflecting the density of leaf tissue), as well as a growth-related trait, all other traits are related to plant resource acquisition and carbon storage [46]. Higher biomass, height, chlorophyll content, and shoot biomass values indicate fast resource use and subsequently fast growth [47]. High root-to-shoot biomass ratio indicate preferential allocation of resources to belowground organs. For plant resistance traits, we considered the average larval weight gain of S. littoralis caterpillars per plant. Therefore, plant functional traits (size, biomass, chlorophyll content, and SLA) would inform on plant growth and carbon storage, while trichomes and S. littoralis performance would inform on physical and, indirectly, chemical defenses [2]. We did not specifically measure tomato plants' secondary metabolites as a defense mechanism, since we consider S. littoralis performance as the integrated outcome of the myriad chemical and nutritional responses of the plants under attack. We also did not measure plant endogenous JA, JA-related defense compounds, or JA-specific gene expression in our experiment, as the mutant lines that were used have been carefully assessed in several previous experiments $[32,34,37,48,49]$. Finally, AM fungi root colonization was measured by staining about $1 \mathrm{~g}$ of fresh root tissue per plant using $1.5 \mathrm{~mL}$ of $\mathrm{KOH} 10 \%$ and blanching for $45 \mathrm{~min}$ in $90{ }^{\circ} \mathrm{C}$ water. Root samples were then rinsed and colored with a Tryphan Blue solution $5 \%$ during 60 min in $90^{\circ} \mathrm{C}$ water. Colonization was checked by microscopy on 10 randomly chosen root segments of $1 \mathrm{~cm}$ length and expressed as AM fungi structure $\mathrm{cm}^{-1}$ root length.

\subsection{Statistical Analyses}

All analyses were performed using the R software (version 3.5.2) [50].

\subsubsection{Plant Traits}

To assess the effect of plant type, AM fungi inoculation and herbivory on plant growth and defense, the seven plant traits (plant size, aerial biomass, root biomass, root: shoot ratio, chlorophyll content, SLA, and trichome density) were compared across the 12 combinatory treatments: plants type (G) def-1, WT, 35S::PS by AM fungi (M, AM-inoculated, or un-inoculated plants) by herbivory ( $\mathrm{H}$, with $S$. littoralis herbivory, or undamaged), using a three-way multivariate analysis of variance (MANOVA, implemented with Wilks' lambda test), followed by three-way univariate analyses of variance (ANOVAs) to test for individual main effects. 


\subsubsection{Resistance}

Two-way ANOVAs were used to test the interactive effect of the plant type (G), the AM fungi treatment $(\mathrm{M})$, the interaction $(\mathrm{G} \times \mathrm{M})$ on larval biomass, and larval survival. In addition, to estimate larval growth response to AM fungi inoculation across the three different tomato type, we used standardized effect size (SES), calculated based on Cohen's d metric using the effsize function in the effsize package in R [51]. The figure obtained with the effect sizes aims at representing if larval growth rates on the different tomato plants respond positively or negatively to AM fungi inoculation, as well as to report the magnitude of the response. A 95\% of confidence interval bar that deviates from zero shows a significant effect of treatment (positive or negative effect of AM fungi inoculation) [52]. While the barplot (see Results) allowed extrapolating the relative effect of AM fungi within each tomato plant type, standardize effect size gave information about the strength of the AM fungal treatment taking in account the common variance across un-inoculated and AM-inoculated plants.

\subsubsection{AM-Colonization}

AM colonization rates between different plant type and herbivory treatment were compared using a two-way ANOVA.

Tukey's mean separation tests were performed to evaluate differences within and among treatments for the plant trait, the resistance, and AM-colonization.

\subsubsection{Multivariate Analysis}

To visualize the dissimilarities among treatments based on the different measured dependent variables (i.e., plant functional traits), a non-metric multidimensional scaling (NMDS) plot was calculated using Bray-Curtis dissimilarities indices (metaMDS function). The relation of the NMDS ordination plot based on the plant traits with larval biomass was visualized using the ordisurf function. The multivariate correlation between larval biomass and the seven plant functional traits (plant size, aerial biomass, root biomass, root:shoot ratio, chlorophyll content, SLA, trichome density, and AM root colonization) was evaluated with the envfit function. All the functions in the multivariate analyses were used in the vegan package (version 2.0.10) [53].

Finally, to explore the relative contribution of the entire measured plant functional traits on the performance of $S$. littoralis caterpillars, we performed a stepwise model selection using AIC in both directions for both larval biomass and larval survival using the step function, followed by a multiple linear regression with the best fitted predictors. We examined the relationship between the single selected predictors and larval performance using the residuals obtained from the relationship between larval performance (larval biomass and survival) and the other selected predictors [54]. Using residuals values statistically controls for the effect of other factor included in the multiple regression, to reveal the contribution of each single predictor.

\section{Results}

\subsection{Plant Functional Traits}

The three-way MANOVA revealed a significant multivariate main effect for the tomato plant type (G; Wilks' $\left.\lambda=0.14, F_{14,94}=10.89, p<0.001\right)$, the AM fungi treatment $(\mathrm{M}$; Wilks' $\lambda=0.67$, $\left.F_{7,47}=3.34, p<0.01\right)$, and for the triple interaction term plant type-AM fungi-herbivory $(\mathrm{G} \times \mathrm{M} \times \mathrm{H}$; Wilks' $\left.\lambda=0.53, F_{14,94}=2.48, p<0.01\right)$. Given the significance of the test, the univariate main effects were examined for each variable, independently (Table 1$)$. 
Table 1. Three-way interaction ANOVAs table on tomato plant growth and defense traits and two-way interaction ANOVA on AM-colonization of plant roots. Factors include (G) tomato plant type: JA expression deficient plants (def-1), wild-type (WT) plants, and JA constitutive expression plants (35S::PS); (M) inoculation or not with the AM fungus R. irregularis, (H) herbivory attack or not by $S$. littoralis caterpillar. Plant traits and root colonization were measured after eight weeks of plant growth. Bold indicate significant effect $(p<0.05)$.

\begin{tabular}{|c|c|c|c|c|}
\hline Response Variable & Factor & d.f. & $F_{\mathrm{x}, \mathrm{y}}$ & $p$ \\
\hline \multirow[t]{8}{*}{ Plant size $(\mathrm{cm})$} & Genotype (G) & 2 & 23.33 & $<0.001$ \\
\hline & AM fungi (M) & 1 & 0.14 & 0.71 \\
\hline & Herbivore $(\mathrm{H})$ & 1 & 0.29 & 0.59 \\
\hline & $\mathrm{G} \times \mathrm{M}$ & 2 & 4.17 & $<0.05$ \\
\hline & $\mathrm{G} \times \mathrm{H}$ & 2 & 0.10 & 0.91 \\
\hline & $\mathrm{M} \times \mathrm{H}$ & 1 & 0.04 & 0.84 \\
\hline & $\mathrm{G} \times \mathrm{M} \times \mathrm{H}$ & 2 & 2.75 & 0.07 \\
\hline & Residuals (R) & 53 & & \\
\hline \multirow[t]{8}{*}{ AG biomass (g) } & G & 2 & 10.7 & $<0.001$ \\
\hline & M & 1 & 1.85 & 0.18 \\
\hline & $\mathrm{H}$ & 1 & 1.41 & 0.24 \\
\hline & $\mathrm{G} \times \mathrm{M}$ & 2 & 1.71 & 0.19 \\
\hline & $\mathrm{G} \times \mathrm{H}$ & 2 & 0.05 & 0.95 \\
\hline & $\mathrm{M} \times \mathrm{H}$ & 1 & 0.72 & 0.40 \\
\hline & $\mathrm{G} \times \mathrm{M} \times \mathrm{H}$ & 2 & 0.94 & 0.40 \\
\hline & $\mathrm{R}$ & 53 & & \\
\hline \multirow[t]{8}{*}{ Root biomass (mg) } & G & 2 & 30.86 & $<0.001$ \\
\hline & M & 1 & 0.03 & 0.88 \\
\hline & $\mathrm{H}$ & 1 & 1.05 & 0.31 \\
\hline & $\mathrm{G} \times \mathrm{M}$ & 2 & 0.22 & 0.83 \\
\hline & $\mathrm{G} \times \mathrm{H}$ & 2 & 3.99 & $<0.05$ \\
\hline & $\mathrm{M} \times \mathrm{H}$ & 1 & 0.66 & 0.42 \\
\hline & $\mathrm{G} \times \mathrm{M} \times \mathrm{H}$ & 2 & 0.37 & 0.69 \\
\hline & $\mathrm{R}$ & 53 & & \\
\hline \multirow[t]{8}{*}{ Root:shoot } & G & 2 & 80.00 & $<0.001$ \\
\hline & M & 1 & 0.65 & 0.42 \\
\hline & $\mathrm{H}$ & 1 & 0.33 & 0.57 \\
\hline & $\mathrm{G} \times \mathrm{M}$ & 2 & 0.42 & 0.66 \\
\hline & $\mathrm{G} \times \mathrm{H}$ & 2 & 2.56 & 0.09 \\
\hline & $\mathrm{M} \times \mathrm{H}$ & 1 & 2.18 & 0.15 \\
\hline & $\mathrm{G} \times \mathrm{M} \times \mathrm{H}$ & 2 & 1.83 & 0.17 \\
\hline & $\mathrm{R}$ & 53 & & \\
\hline \multirow[t]{8}{*}{ Chlorophyll content } & G & 2 & 4.81 & $<0.05$ \\
\hline & M & 1 & 5.93 & $<0.05$ \\
\hline & $\mathrm{H}$ & 1 & 2.32 & 0.13 \\
\hline & $\mathrm{G} \times \mathrm{M}$ & 2 & 1.62 & 0.21 \\
\hline & $\mathrm{G} \times \mathrm{H}$ & 2 & 0.09 & 0.91 \\
\hline & $\mathrm{M} \times \mathrm{H}$ & 1 & 0.75 & 0.39 \\
\hline & $\mathrm{G} \times \mathrm{M} \times \mathrm{H}$ & 2 & 1.36 & 0.27 \\
\hline & $\mathrm{R}$ & 53 & & \\
\hline \multirow[t]{8}{*}{ SLA $\left(\mathrm{mm}^{2} / \mathrm{mg}\right)$} & G & 2 & 1.26 & 0.29 \\
\hline & M & 1 & 19.55 & $<0.001$ \\
\hline & $\mathrm{H}$ & 1 & 1.58 & 0.21 \\
\hline & $\mathrm{G} \times \mathrm{M}$ & 2 & 0.76 & 0.47 \\
\hline & $\mathrm{G} \times \mathrm{H}$ & 2 & 4.55 & $<0.05$ \\
\hline & $\mathrm{M} \times \mathrm{H}$ & 1 & 0.94 & 0.34 \\
\hline & $\mathrm{G} \times \mathrm{M} \times \mathrm{H}$ & 2 & 3.74 & $<0.05$ \\
\hline & $\mathrm{R}$ & 53 & & \\
\hline
\end{tabular}


Table 1. Cont.

\begin{tabular}{ccccc}
\hline Response Variable & Factor & d.f. & $\boldsymbol{F}_{\mathbf{x}, \mathbf{y}}$ & $\boldsymbol{p}$ \\
\hline Trichome density & $\mathrm{G}$ & 2 & 23.44 & $<\mathbf{0 . 0 0 1}$ \\
& $\mathrm{M}$ & 1 & 0.11 & 0.74 \\
& $\mathrm{H}$ & 1 & 0.63 & 0.43 \\
& $\mathrm{G} \times \mathrm{M}$ & 2 & 0.12 & 0.88 \\
& $\mathrm{G} \times \mathrm{H}$ & 2 & 0.03 & 0.97 \\
& $\mathrm{M} \times \mathrm{H}$ & 1 & 0.38 & 0.54 \\
& $\mathrm{G} \times \mathrm{M} \times \mathrm{H}$ & 2 & 1.88 & 0.16 \\
& $\mathrm{R}$ & 53 & & \\
\hline AMF colonization & $\mathrm{G}$ & 2 & 5.96 & $<\mathbf{0 . 0 1}$ \\
& $\mathrm{H}$ & 1 & 0.12 & 0.73 \\
& $\mathrm{G} \times \mathrm{H}$ & 2 & 0.36 & 0.70 \\
& $\mathrm{R}$ & 27 & & \\
\hline
\end{tabular}

Variation in the JA phytohormonal pathway significantly affected the growth of tomato plants. The WT and the 35S::PS plants were on average 11\% and 13\% taller (Figure 1a), produced $16.5 \%$ and $26.5 \%$ more aerial biomass (Figure $1 \mathrm{~b}$ ), and produced $5 \%$ and $9.5 \%$ more chlorophyll in their leaves (Figure 1e) than the def-1, respectively (Table 1). An opposite trend was observed for the root biomass and the root:shoot ratio. JA deficient tomato plants (def-1) significantly allocated more biomass to the roots (Table 1). Root biomass (Figure 1c) and the root:shoot ratio (Figure 1d) on def-1 plants were $35 \%$ and $47 \%$ higher than in $355 \%: P S$ and WT plants, respectively. AM fungal colonization significantly increased the leaf chlorophyll content, which overall was $8 \%$ higher than plants without AM fungi (Table 1). In addition, a significant interaction between plant type and AM fungi inoculation revealed that plant size in JA-accumulating plants (35S::PS) was decreased following AM fungal inoculation compared to JA-deficient plants (def-1) and WT plants. AM fungal inoculation overall significantly decreased SLA of JA-deficient plants (def-1) by $4.4 \%$ and 3.9\% compared to WT and JA-accumulating ones (35S::PS), respectively (Table 1). Herbivory treatment significantly affected only SLA. Although the effect emerged only in a plant type and plant type by AM fungi treatment specific fashion (Table 1). Figure $1 \mathrm{f}$ shows that SLA of JA-deficient tomato plants (def-1) inoculated with AM fungi was slightly higher when free from larvae compared to infested plants, whereas the opposite pattern was visible on WT plants.

\subsection{AMF Colonization}

None of the un-inoculated plants showed traces of AM fungi colonization. For the inoculated plants, the two-way ANOVA revealed a significant effect of the tomato plant type (G) on AM fungi colonization of the roots $\left(F_{2,27}=5.96, p<0.01\right)$.

JA accumulating plants (35S::PS) showed a significant reduction in AM fungi colonization of the roots compared to JA-deficient plants (def-1), which were $45 \%$ more colonized by AM fungi (Figure 2 , Table 1). Herbivory treatment $(\mathrm{H})$ did not significantly affect AM fungi colonization in plant roots. Finally, AM fungi colonization, considered as a continuous variable in a multivariate linear model, was significantly positively correlated with larval biomass $\left(F_{1,16}=18.75, p<0.001\right)$, larval survival $\left(F_{1,16}=9.46, p<0.01\right)$, and marginally with trichome density $\left(F_{1,16}=3.42, p<0.08\right)$, but not with SLA $\left(F_{1,16}=0.004, p=\mathrm{ns}\right)$. 

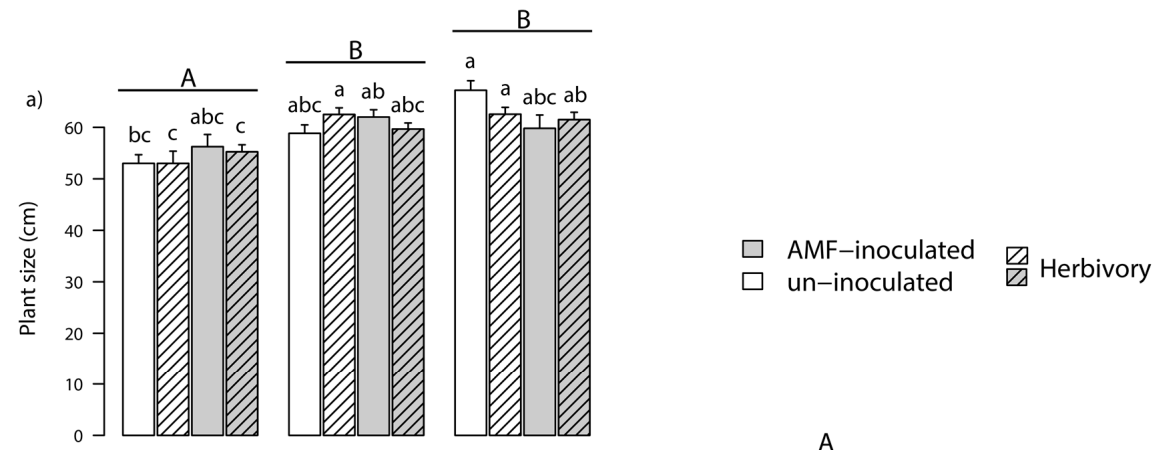
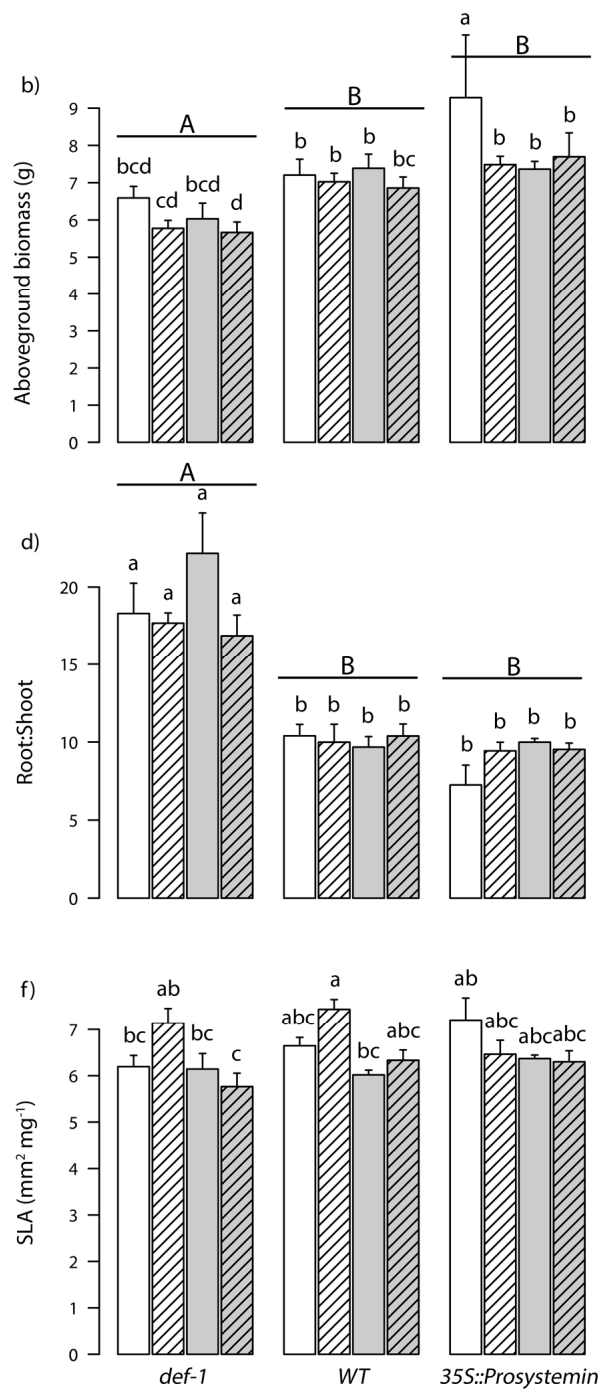
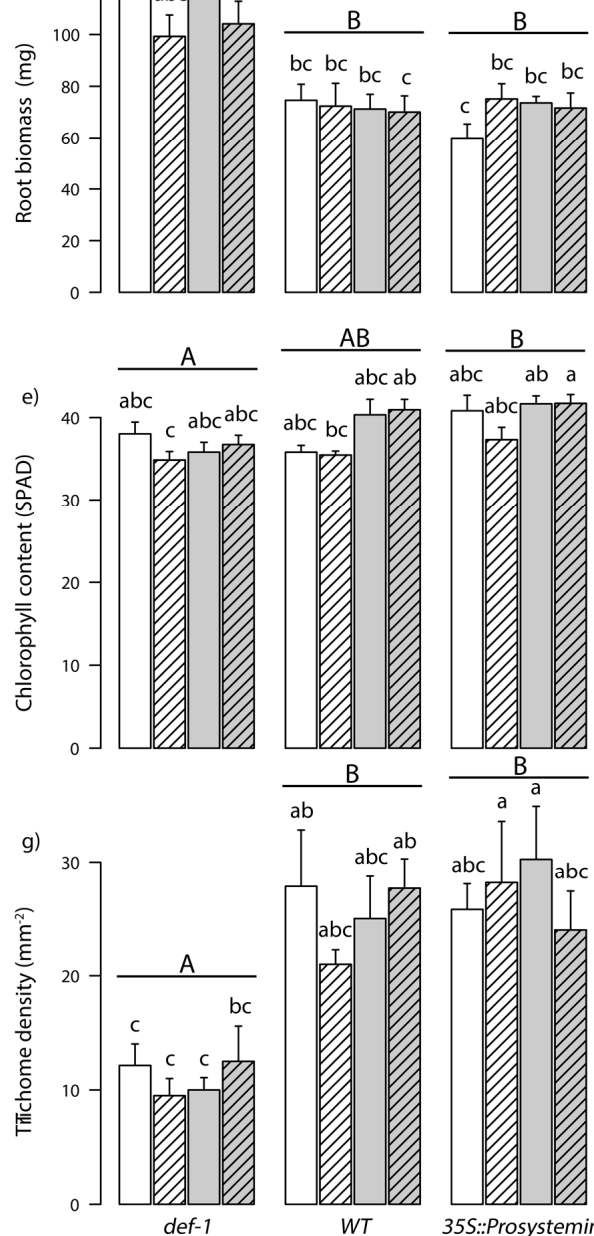

WT
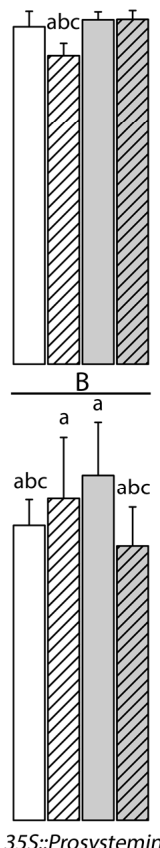

Figure 1. Tomato plants growth and defense traits (mean + standard error (SE)), including (a) plant size $(n=102)$, (b) plant biomass $(n=100)$, (c) roots biomass $(n=65)$, (d) roots:shoots ratio $(n=65)$, (e) chlorophyll content $(n=103)$, (f) specific leaf area (SLA; $n=66)$, (g) and trichome density $(n=66)$. The plants have different genotype: jasmonic acid (JA) expression deficient plants (def-1), wild-type plants (WT), and prosystemin constitutive expression (35S::prosystemin) plants. Traits were measured after eight weeks of growth. Half of the plants were either inoculated with Arbuscular mycorrhizal fungi (AMF) (grey bars) or left un-inoculated (white bars). Dashed line bars represent plants treated with $S$. littoralis for $7 \mathrm{~d}$. Lower case letters above bars represent pairwise significant difference across all treatments' combination after Tukey's mean separation test $(p<0.05)$. Capital letters above bars represent difference across tomato genotypes. 


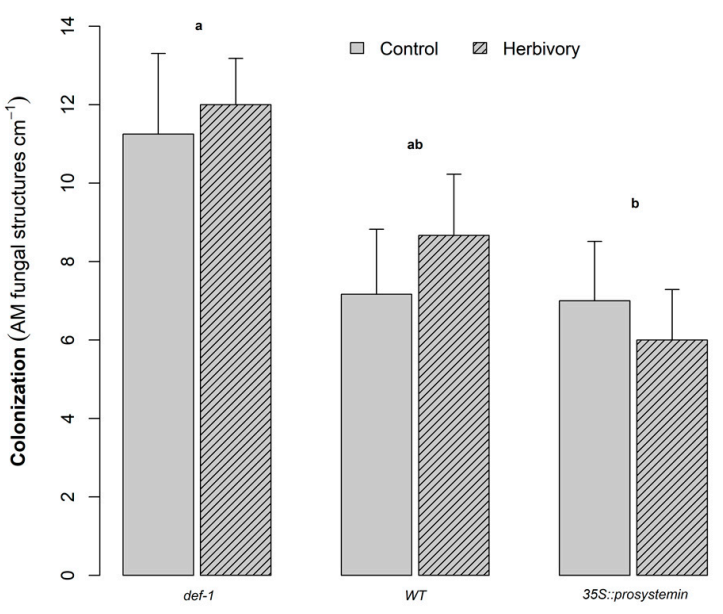

Figure 2. AM root colonization (mean $+\mathrm{SE}, n=6$ ) depending on herbivory treatment and plant type: JA expression deficient plants (def-1), wild-type plants (WT), and prosystemin constitutive expression plants (35S::prosystemin). Root colonization was measured after eight weeks of growth. Letters above the bars indicate significant difference among plant types according to Tukey's mean separation test $(p<0.05)$.

\subsection{Defense and Resistance Traits}

Variation in the JA phytohormonal pathway had a significant impact on trichome density. WT plants and the plants which constitutively express prosystemin (35S::PS) produced on average $56 \%$ and $69 \%$ more trichomes per unit of surface than JA-deficient (def- 1 ) plants, respectively (Figure 1g, Table 1). Herbivore performance was driven by both plant type and AM fungi inoculation. The average larval biomass (Figure 3a) and survival (Figure 3b) were strongly affected by plant type (G; $F_{2,66}=71.64, p<0.001, F_{2,66}=46.31, p<0.001$ ) and were on average $43 \%$ and $70 \%$ (for larval biomass), and $56 \%$ and $51 \%$ (for survival) lower in WT and JA-accumulating plants (35S:::PS), respectively, than on JA-deficient plants (def-1) (Figure 3a).
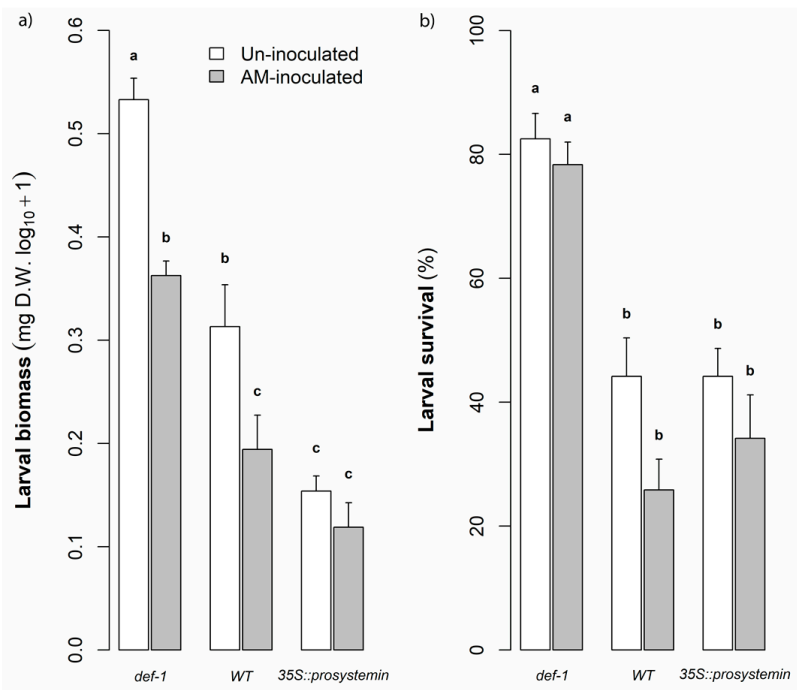

Figure 3. Effect of plant type and AM fungi treatment (mean $+\mathrm{SE}, n=12)$ on (a) larval biomass (mg D.W., $\left.\log _{10}+1\right)$ and (b) larval survival (\%). Grey solids and dotted black lines represent AM-inoculated and un-inoculated plant respectively. Plant type: JA expression deficient plants (def-1), wild-type plants (WT) and prosystemin constitutive expression plants (35S::prosystemin). Larvae were placed on plants after seven weeks of growth and larval biomass and mortality were measured after one week of feeding on plants. Letters above the bars indicate significant difference according to Tukey's mean separation test $(p<0.05)$. 
Likewise, harboring AM fungi significantly decreased the larval biomass and survival $\left(\mathrm{M} ; F_{1,66}=25.39, p<0.001, F_{1,66}=6.47, p<0.05\right.$ ) about $32 \%$ and $19 \%$ compared to un-inoculated plants, respectively. In addition, the interaction between plant type and AM fungi treatment was significant $\left(\mathrm{G} \times \mathrm{M} ; F_{1,66}=3.39, p<0.05\right)$ for the larval biomass (Figure 3a), indicating that AM fungi inoculation affect larval biomass in a plant type-specific fashion. On JA-deficient (def-1) and wild-type (WT) plants treated with AM fungi the larval biomass was significantly reduced by $32 \%$ and $38 \%$, respectively, when compared to un-inoculated plant (relative intensity of AM fungi effect). On the contrary, for JA-accumulating (35S::PS) plants, larval biomass was similar between AM fungi treated plants and un-inoculated plant. In addition, in terms of absolute larval biomass, caterpillars feeding, on un-inoculated WT plants performed the same as larvae feeding on JA-deficient (def-1) AM-inoculated plants, and larvae feeding on un-inoculated JA-accumulating plants (35S::PS), which performed similar to those feeding on AM-inoculated WT plants (Figure 3a). Finally, standardized effect size (SES) analysis illustrated that overall larval biomass responds negatively to AM fungi treatment across all the three tomato plant types, but the response is significant only in def- 1 and WT plants ( $95 \%$ confidence interval bar does not cross the zero line). Additionally, the same analysis showed that the magnitude of the negative response for the larvae is stronger in def- 1 tomato that in WT plants (Figure 4).

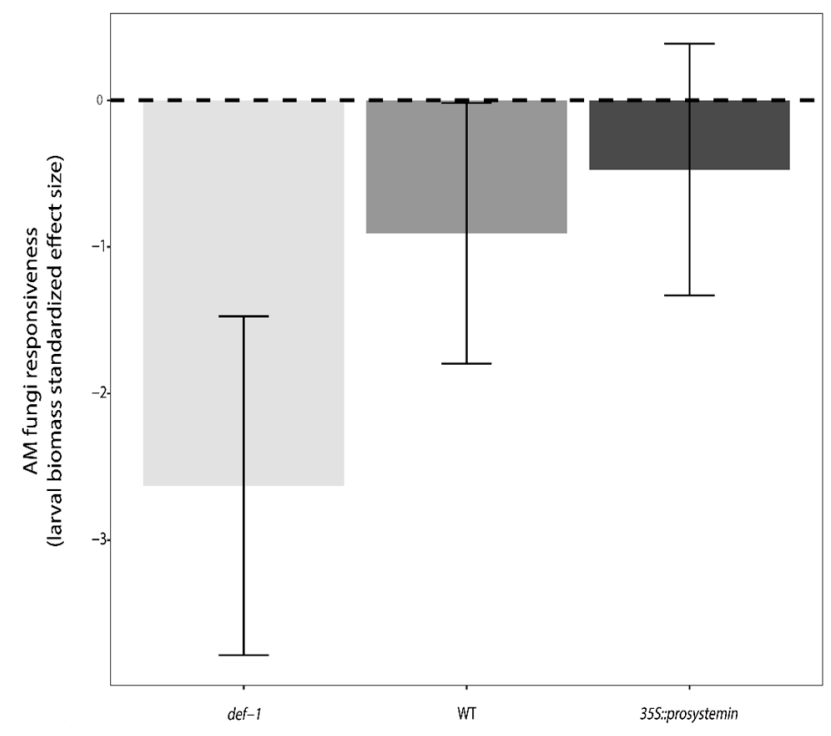

Figure 4. AM fungi responsiveness measure of the three plant type: JA expression deficient plants (def-1), wild-type plants (WT), and prosystemin constitutive expression plants (35S::prosystemin). Different colors represent the three different genotype. Effect size were based on the average larval biomass $(n=12)$. Negative standardized effect size indicate that larval biomass negatively responded to AM fungi presence in plant roots.

\subsection{Multivariate Analyses}

As visualized in the Non-metric multidimensional scaling (NMDS) ordination plot based on plant functional traits, the discrimination of the different treatments is strongly based on the AM fungi root colonization along the $\mathrm{x}$-axis (Figure 5). 


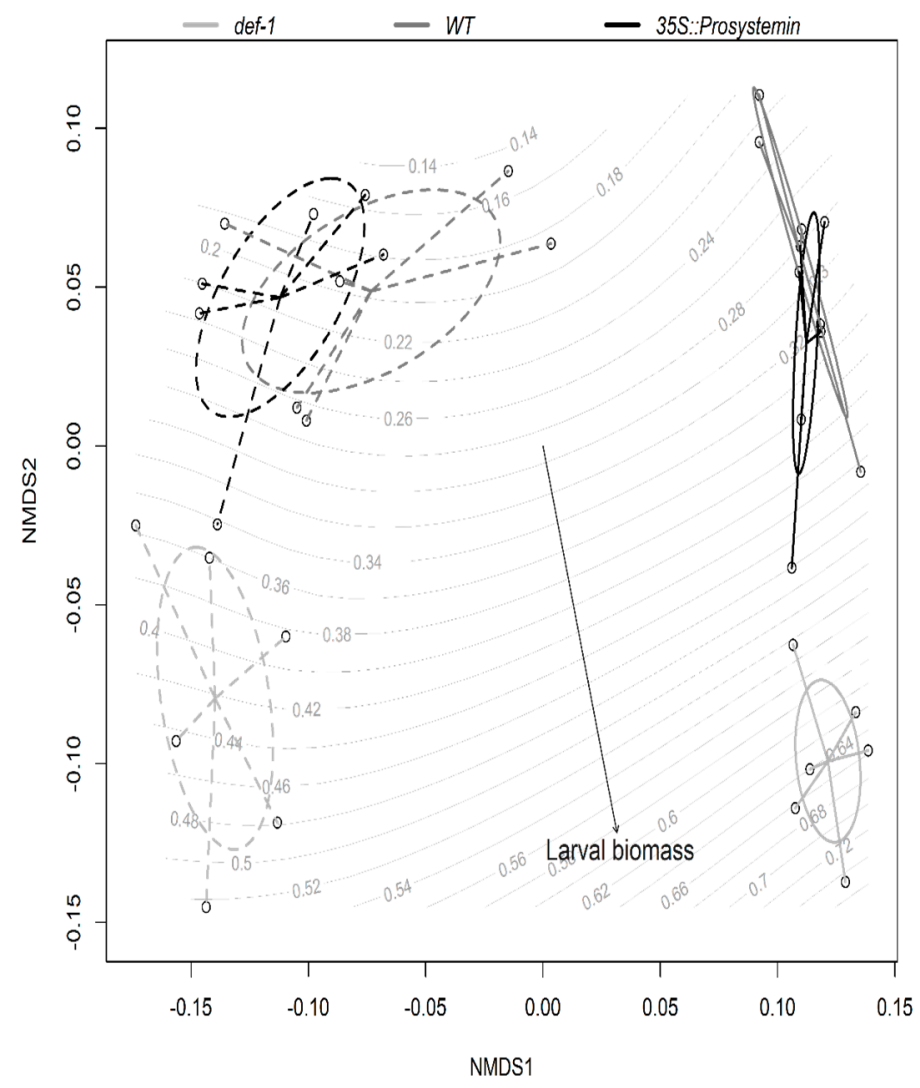

Figure 5. Non-metric multidimensional scaling (NDMS) ordination of different tomato plant type colonized or not by AM fungi on plant functional traits. Larval biomass of S. littoralis feeding on different plant treatments is overlaid as response curves in grey. Treatments are enclosed by ovals according to plant type: JA expression deficient plants (def-1), wild-type plants (WT), and prosystemin constitutive expression plants (35S::prosystemin) coloured in light grey, dark grey, and black, respectively, and AM fungi treatment dotted ovals for AM-inoculated plant and solid line for un-inoculated plants. $n=35$.

Moreover, the ordination clearly separates plants impaired in the JA production (def-1) versus the WT and the plants expressing constitutively JA (35S::PS) along the y-axis of the NMDS plot (Figure 5). The projection of the larval biomass vector onto the ordination was highly significant (envfit: $R^{2}=0.53, p=0.001$, stress value $=0.06, \mathrm{~K}$ (number of dimensions) $=2$ ), indicating the differential larval growth, particularly along the JA-producing versus non-JA-producing plant axis. The multiple regression analysis showed a positive correlation of larval biomass with SLA and root:shoot ratio (Figure 6a,b) (overall model, Adj $R^{2}=0.46, F_{2,32}=15.21, p<0.001$, SLA coefficient $=0.09, p=0.02$, root:shoot coefficient $=0.04, p<0.001$ ) and larval survival with root:shoot ratio (Figure $6 \mathrm{~d}$ ) (overall model, Adj $R^{2}=0.39, F_{2,32}=11.91, p<0.001$, root:shoot coefficient $=5.31, p<0.001$, aboveground biomass coefficient $=6.78, p$ non-significant). In contrast, aboveground biomass was not correlated with larval survival that was selected as predictor by step AIC analysis and included to calculate residual larval survival to visualize the relationship with root: shoot ratio. All of the other measured traits (plant size, root biomass, chlorophyll content, and trichome density) showed no correlation with caterpillar performance. 


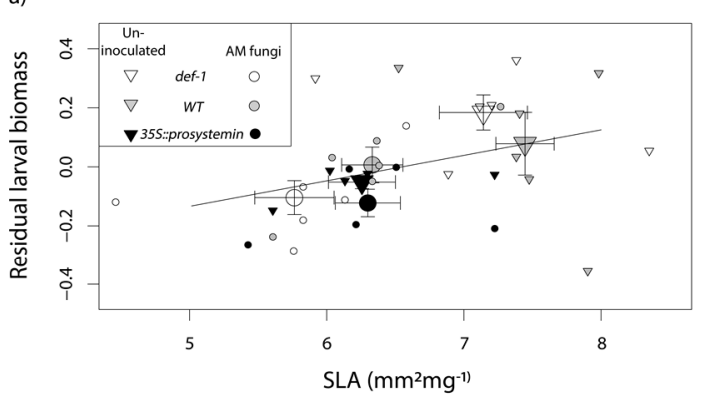

c)

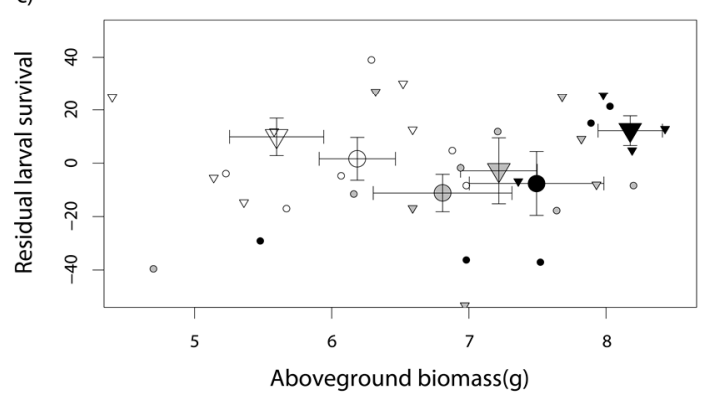

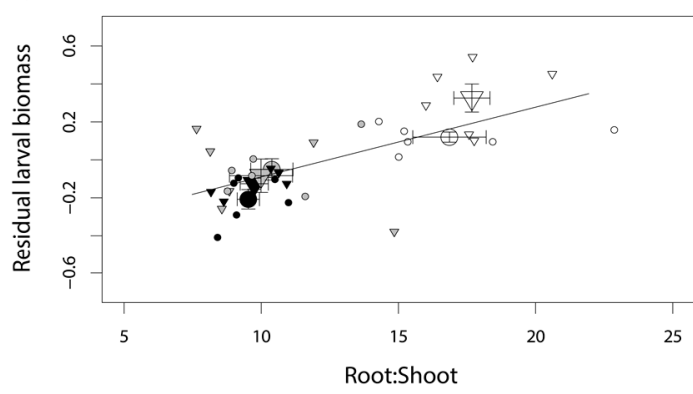

d)

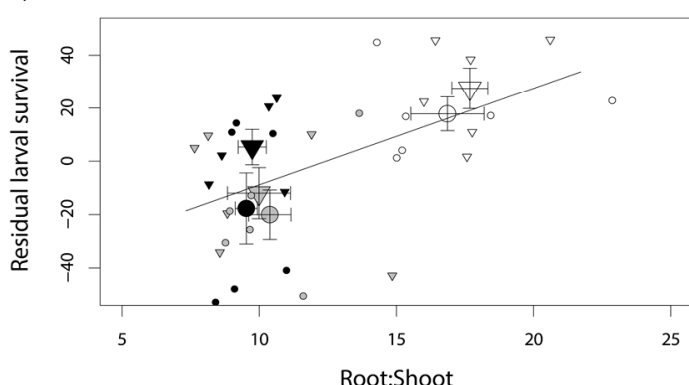

Figure 6. Effect of plant growth and defensive traits on S. littoralis caterpillar performance. Seven plant traits were included in the analysis but only the significant predictors following stepAIC selection are illustrated: (a) SLA and (b) root:shoot to explain larval biomass and (c) aboveground biomass and (d) root:shoot to explain larval survival. Residual larval biomass and larval survival refers to the statistical model with the other factor in the analysis. Larger points represent mean \pm SE. The plants have different genotype shown with different colors: JA expression deficient plants (def-1) in white, wild-tape plants (WT) in grey, and JA over-accumulating plants (35S::prosystemin) in black. Different geometrical figures represent AM-fungal treatment: triangles represent un-inoculated plants and circles AM-inoculated plants $(n=36)$.

\section{Discussion}

We tested for the interactive effects of a JA production and mycorrhizal inoculation (R. irregularis) on tomato plants when challenged with a generalist insect herbivore (S. littoralis caterpillars). Overall, JA-deficient plants performed worst in practically all growth and resistance traits, but in line with the complementarity of functions hypothesis, these plants benefitted more by AM fungal inoculation than plants with a functional JA pathway when measuring resistance against the generalist caterpillar feeding.

\subsection{Effect of JA on Plant Functional Traits}

We found that JA-producing plants produced more biomass than then other two tomato genotypes and that JA-producing plants produced twice the number of trichomes than the JA-deficient plants [48]. JA-dependent trichome production, through expression of several JA-responsive genes involved in plant defense activation, has been shown in several systems including $A$. thaliana $[55,56]$ and tomato plants $[57,58]$. Such enhanced growth under high defense investment might counter the classically postulated growth-defense trade-off, indicating plants that invest more in defenses should grow less, and vice-versa [59]. Similarly, it has been shown that exogenous treatment of tomato plants with JA does not negatively affect aboveground biomass production [60]. On the other hand, other studies have shown that tomato plants treated with exogenous JA produced lower number of fruits with less seeds compared to untreated plants [61], which indicates trade-offs between defenses and reproduction. Therefore, trade-offs are highly context dependent and visible only under specific environmental conditions [5], as well as variable across plant traits. To summarize, our experiment concords with 
previous results on the same system, indicating that JA signaling pathway strongly mediates changes in plant trait expression, resource allocation, and development. However, this cannot be fully confirmed here, since ectopic expressions of prosystemin have been previously observed in different plant species altered in JA-biosynthetic pathway, and thus, the differences observed in in our prosystemin line cannot be solely attributed to greater JA accumulation $[62,63]$.

\subsection{Effect of JA on AM Fungal Colonization}

Tomato plants with reduced JA accumulation after wounding showed higher AM root colonization compared to wild type and prosystemin-hyperaccumulating tomato plants. A relevant number of studies has shown that tomato plants with deficient JA perception and/or biosynthesis showed reduced $[14,15,64]$, increased $[65,66]$, or no difference in root colonization when compared to wild types $[14,33]$. Furthermore, such effect is also dependant on plant species. JA levels reduced AM fungal colonization in rice [67], Tropaeolus majus L., and Carica papaya L. [68], but enhanced AM fungal colonization in Allium sativum L. [69] and Medicago truncatula (Gaetn) [70,71].

The model of mycorrhizal colonization proposes that a plant recognizes a mycorrhizal partner as being more or less parasitic depending on how much of the molecular recognition patterns are shared with root biotrophic pathogens [72]. Consequently, if the AM fungus appears to be parasitic, it might trigger a similar plant immune system that would be displayed against pathogen invaders [73]. It was shown that once the fungus enters the cortical cells of the roots, JA levels increase in order to regulate the symbiosis $[74,75]$. Our results that show a reduction of AM fungal colonization in prosystemin-overaccumulating plants confirm this model of JA-regulating fungal symbiosis [65]. Nonetheless, the exact regulation of the mycorrhization process is also dependent on other phytohormones (SA, ABA, ET (ethylene), oxo-phytodienoic acid (OPDA), and JA-Ile), ultimately driving such strong context-dependency [76]. For instance, an induction of JA by AM fungi could be inhibited by the crosstalk with the induction of SA by other organisms [77].

\subsection{Interactive Effects of JA and AM Fungi on Plant Growth and Resistance}

AM fungi favor nutrient acquisition in exchange of photosynthate [16]. When such nutrient exchanges are optimal and the mutualistic symbiosis is stable [78-82], the growth of mycorrhizal plants is favored. However, such a resource exchange model could be easily modified by the genetic identity of the partners $[31,83,84]$ and is highly context dependent $[85,86]$. Here, chlorophyll content was higher in mycorrhizal plants. Increased chlorophyll content in the leaves of mycorrhizal plant [87] indicates higher nitrogen content [88]. While photosynthetic activity and nitrogen content are generally positively correlated with SLA [89], we observed that when mycorrhized, plants decrease SLA levels. This implies that AM fungi can reverse classically-postulated traits correlations in plants [90]. All other growth-related traits (plant size and biomass) showed no variation depending on the mycorrhizal status, while plant resistance did so. More specifically, mycorrhizal plants were overall more resistant, when considering either larval biomass or larval survival. Our results agree with the general predictions of AM fungi mediating increased plant defenses against generalist chewing herbivores [91]. Moreover, similar work on tomato mutant lines, but using another noctuid generalist caterpillar Helicoverpa arimigera, and other mutant lines deficient in JA accumulation or perception (spr2 and jai1) demonstrated such AM fungi-mediated increased resistance by a priming effect, in which pre-inoculated plants showed a faster and stronger JA-related gene expression compared to un-inoculated plants when attacked by the caterpillars [14]. Priming of defense signaling pathway by root-associated beneficial microbes has been postulated $[13,25,92]$ and is observed in the tomato systems [93]. Here, we observed that the JA-deficient plants benefit more in terms of defense to the AM fungal treatment than JA overproducing plants. This would refute a potential JA priming event. However, because in wild-type plants the differences in caterpillar biomass between AM fungi-inoculated plants and un-inoculated plants remain significant (see also Figure 6), we cannot 
completely rule out a priming effect mediated by our strain of $R$. irregularis. For thoroughly testing this, it would require a dense time-course measurement of JA-related gene expression pattern.

The multivariate linear model also revealed a positive effect of SLA on larvae biomass. SLA, in addition to inform on the potential growth rate of the plant, can also provide insight about plants' investment in structural defenses [94], in which, low SLA values (i.e., thicker leaves) have been often correlated with higher resistance $[89,95,96]$. Low leaf SLA may require a more intense mechanical power by the herbivore in order to access plant nutrients [97]. Different studies also showed (in line with our results) that AM fungi tend to lower SLA values in plants [98,99]. Here, we showed that def- 1 plants, when colonized by AM fungi and when damaged by herbivores, lower SLA values more than the other two tomato lines, which might also contribute explaining the higher negative response of the caterpillar feeding on JA-impaired plant when colonized by AM fungi.

Finally, we observed a positive correlation between AM root colonization and larval performance. This may be counterintuitive, since we provide evidence that def- 1 tomato plants seem to profit more from AM fungi in terms of protection against herbivores. An eventual negative dose-dependent effect of AM colonization on herbivore performance, as shown by Vannette and Rasmann [23] on belowground herbivores, was probably masked by the strong effect of the different tomato lines on AM fungal colonization in our study.

\section{Conclusions}

Overall, we observed a complementary effect of AM fungi and endogenous plant defense on plant resistance; however, generalizations are yet to be fully achieved. Manipulating plant and fungus genetic variation across multiple environments and across natural genetic variation of plants and AM fungi will help to produce more generalizable predictions to be included in future agro-ecological programs for more sustainable pest control.

Author Contributions: S.R. conceived and designed the experiment. L.F. collected and analyzed the data, and wrote the manuscript. Both authors contributed to the writing of the final draft.

Funding: This work was financed with Swiss National Science Foundation grants PZ00P3_131956 and 31003A_159869 to S.R.

Acknowledgments: We thank Jennifer Thaler for providing the mutant tomato seeds. Alban Sadiku and Quentin Aeberli for their help with the greenhouse experiment and data collection.

Conflicts of Interest: The authors declare no conflict of interest.

\section{References}

1. Strong, D.R.; Lawton, J.H.; Southwood, R. Insects on Plants: Community Patterns and Mechanisms; Blackwell Scientific: London, UK, 1984.

2. Schoonhoven, L.M.; van Loon, J.J.A.; Dicke, M. Insect-Plant Biology; Oxford University Press: Oxford, UK, 2005.

3. Farmer, E.E. Leaf DefenceDefense; Oxford University Press: Oxford, UK, 2014.

4. War, A.R.; Paulraj, M.G.; Ahmad, T.; Buhroo, A.A.; Hussain, B.; Ignacimuthu, S.; Sharma, H.C. Mechanisms of plant defense against insect herbivores. Plant Signal Behav. 2012, 7, 1306-1320. [CrossRef]

5. Pieterse, C.M.J.; Zamioudis, C.; Does, D.V.; Van Wees, S.C.M. Signalling Networks Involved in Induced Resistance. In Induced Resistance for Plant Defense; John Wiley \& Sons, Ltd.: Hoboken, NJ, USA, 2014; pp. 58-80. [CrossRef]

6. Giron, D.; Frago, E.; Glevarec, G.; Pieterse, C.M.J.; Dicke, M. Cytokinins as key regulators in plant-microbe-insect interactions: Connecting plant growth and defencedefense. Funct. Ecol. 2013, 27, 599-609. [CrossRef]

7. Robert-Seilaniantz, A.; Grant, M.; Jones, J.D.G. Hormone Crosstalk in Plant Disease and Defense: More Than Just JASMONATE-SALICYLATE Antagonism. Annu. Rev. Phytopathol. 2011, 49, 317-343. [CrossRef] [PubMed] 
8. Farmer, E.E.; Alméras, E.; Krishnamurthy, V. Jasmonates and related oxylipins in plant responses to pathogenesis and herbivory. Curr. Opin. Plant Biol. 2003, 6, 372-378. [CrossRef]

9. Wasternack, C.; Stenzel, I.; Hause, B.; Hause, G.; Kutter, C.; Maucher, H.; Neumerkel, J.; Feussner, I.; Miersch, O. The wound response in tomato-role of jasmonic acid. J. Plant Physiol. 2006, 163, 297-306. [CrossRef] [PubMed]

10. Conrath, U.; Beckers, G.J.M.; Flors, V.; García-Agustín, P.; Jakab, G.; Mauch, F.; Newman, M.-A.; Pieterse, C.M.J.; Poinssot, B.; Pozo, M.J.; et al. Priming: Getting Ready for Battle. Mol. Plant-Microbe Interact. 2006, 19, 1062-1071. [CrossRef] [PubMed]

11. Frost, C.J.; Mescher, M.C.; Carlson, J.E.; De Moraes, C.M. Plant Defense Priming against Herbivores: Getting Ready for a Different Battle. Plant Physiol. 2008, 146, 818-824. [CrossRef]

12. Ton, J.; De Vos, M.; Robben, C.; Buchala, A.; Metraux, J.P.; Van Loon, L.C.; Pieterse, C.M.J. Characterization of Arabidopsis enhanced disease susceptibility mutants that are affected in systemically induced resistance. Plant J. 2002, 29, 11-21. [CrossRef]

13. Pozo, M.J.; Azcon-Aguilar, C. Unraveling mycorrhiza-induced resistance. Curr. Opin. Plant Biol. 2007, 10, 393-398. [CrossRef]

14. Song, Y.Y.; Ye, M.; Li, C.Y.; Wang, R.L.; Wei, X.C.; Luo, S.M.; Zeng, R.S. Priming of anti-herbivore defense in tomato by arbuscular mycorrhizal fungus and involvement of the jasmonate pathway. J. Chem. Ecol. 2013, 39, 1036-1044. [CrossRef]

15. Song, Y.; Chen, D.; Lu, K.; Sun, Z.; Zeng, R. Enhanced tomato disease resistance primed by arbuscular mycorrhizal fungus. Front. Plant Sci. 2015, 6, 786. [CrossRef] [PubMed]

16. Smith, S.E.; Read, D.R. Mycorrhizal Symbiosis; Academic Press: Amsterdam, The Netherlands; New York, NY, USA; Boston, MA, USA, 2008.

17. Cameron, D.D.; Neal, A.L.; van Wees, S.C.; Ton, J. Mycorrhiza-induced resistance: More than the sum of its parts? Trends Plant Sci. 2013, 18, 539-545. [CrossRef]

18. Fritz, M.; Jakobsen, I.; Lyngkjaer, M.F.; Thordal-Christensen, H.; Pons-Kuhnemann, J. Arbuscular mycorrhiza reduces susceptibility of tomato to Alternaria solani. Mycorrhiza 2006, 16, 413-419. [CrossRef] [PubMed]

19. Bennett, A.E.; Alers-Garcia, J.; Bever, J.D. Three-way interactions among mutualistic mycorrhizal fungi, plants, and plant enemies: Hypotheses and synthesis. Am. Nat. 2006, 167, 141-152. [PubMed]

20. Gange, A.C.; West, H.M. Interactions between arbuscular mycorrhizal fungi and foliar-feeding insects in Plantago lanceolata L. New Phytol. 1994, 128, 79-87. [CrossRef]

21. Koricheva, J.; Gange, A.C.; Jones, T. Effects of mycorrhizal fungi on insect herbivores: A meta-analysis. Ecology 2009, 90, 2088-2097. [CrossRef]

22. Kempel, A.; Schmidt, A.K.; Brandl, R.; Schädler, M. Support from the underground: Induced plant resistance depends on arbuscular mycorrhizal fungi. Funct. Ecol. 2010, 24, 293-300. [CrossRef]

23. Vannette, R.L.; Rasmann, S. Arbuscular mycorrhizal fungi mediate below-ground plant-herbivore interactions: A phylogenetic study. Funct. Ecol. 2012, 26, 1033-1042. [CrossRef]

24. Vannette, R.L.; Hunter, M.D. Plant defencedefense theory re-examined: Nonlinear expectations based on the costs and benefits of resource mutualisms. J. Ecol. 2011, 99, 66-76. [CrossRef]

25. Jung, S.C.; Martinez-Medina, A.; Lopez-Raez, J.A.; Pozo, M.J. Mycorrhiza-induced resistance and priming of plant defenses. J. Chem. Ecol. 2012, 38, 651-664. [CrossRef]

26. Pozo, M.J.; Lopez-Raez, J.A.; Azcon-Aguilar, C.; Garcia-Garrido, J.M. Phytohormones as integrators of environmental signals in the regulation of mycorrhizal symbioses. New Phytol. 2015, 205, 1431-1436. [CrossRef]

27. Tao, L.; Ahmad, A.; de Roode, J.C.; Hunter, M.D.; van der Heijden, M. Arbuscular mycorrhizal fungi affect plant tolerance and chemical defencedefenses to herbivory through different mechanisms. J. Ecol. 2016, 104, 561-571. [CrossRef]

28. Vannette, R.; Hunter, M.; Rasmann, S. Arbuscular mycorrhizal fungi alter above- and below-ground chemical defense expression differentially among Asclepias species. Front. Plant Sci. 2013, 4. [CrossRef] [PubMed]

29. Herrera Medina, M.J.; Gagnon, H.; Piché, Y.; Ocampo, J.A.; García-Garrido, J.M.; Vierheilig, H. Root colonization by arbuscular mycorrhizal fungi is affected by the salicylic acid content of the plant. Plant Sci. 2003, 164, 993-998. [CrossRef]

30. Vannette, R.L.; Hunter, M.D. Mycorrhizal fungi as mediators of defencedefense against insect pests in agricultural systems. Agric. For. Entomol. 2009, 11, 351-358. [CrossRef] 
31. Fernandez, I.; Merlos, M.; Lopez-Raez, J.A.; Martinez-Medina, A.; Ferrol, N.; Azcon, C.; Bonfante, P.; Flors, V.; Pozo, M.J. Defense related phytohormones regulation in arbuscular mycorrhizal symbioses depends on the partner genotypes. J. Chem. Ecol. 2014, 40, 791-803. [CrossRef]

32. Howe, G.A.; Lightner, J.; Browse, J.; Ryan, C.A. An octadecanoid pathway mutant (JL5) of tomato is compromised in signaling for defense against insect attack. Plant Cell 1996, 8, 2067-2077. [CrossRef] [PubMed]

33. Sanchez-Romera, B.; Calvo-Polanco, M.; Ruiz-Lozano, J.M.; Zamarreno, A.M.; Arbona, V.; Garcia-Mina, J.M.; Gomez-Cadenas, A.; Aroca, R. Involvement of the def-1 Mutation in the Response of Tomato Plants to Arbuscular Mycorrhizal Symbiosis Under Well-Watered and Drought Conditions. Plant Cell Physiol. 2018, 59, 248-261. [CrossRef]

34. Li, C.; Williams, M.M.; Loh, Y.T.; Lee, G.I.; Howe, G.A. Resistance of cultivated tomato to cell content-feeding herbivores is regulated by the octadecanoid-signaling pathway. Plant Physiol. 2002, 130, 494-503. [CrossRef]

35. Abouelsaad, I.; Renault, S. Enhanced oxidative stress in the jasmonic acid-deficient tomato mutant def-1 exposed to $\mathrm{NaCl}$ stress. J. Plant Physiol. 2018, 226, 136-144. [CrossRef]

36. Thaler, J.S.; Owen, B.; Higgins, V.J. The role of the jasmonate response in plant susceptibility to diverse pathogens with a range of lifestyles. Plant Physiol. 2004, 135, 530-538. [CrossRef]

37. Howe, G.A.; Ryan, C.A. Suppressors of Systemin Signaling Identify Genes in the Tomato Wound Response Pathway. Genetics 1999, 153, 1411-1421.

38. Sun, J.-Q.; Jiang, H.-L.; Li, C.-Y. Systemin/Jasmonate-Mediated Systemic Defense Signaling in Tomato. Mol. Plant 2011, 4, 607-615. [CrossRef]

39. McGurl, B.; Orozco-Cardenas, M.; Pearce, G.; Ryan, C.A. Overexpression of the prosystemin gene in transgenic tomato plants generates a systemic signal that constitutively induces proteinase inhibitor synthesis. Proc. Natl. Acad. Sci. USA 1994, 91, 9799-9802. [CrossRef] [PubMed]

40. Coppola, M.; Corrado, G.; Coppola, V.; Cascone, P.; Martinelli, R.; Digilio, M.C.; Pennacchio, F.; Rao, R. Prosystemin Overexpression in Tomato Enhances Resistance to Different Biotic Stresses by Activating Genes of Multiple Signaling Pathways. Plant Mol. Biol. Report. Ispmb 2015, 33, 1270-1285. [CrossRef]

41. Diaz, J.; ten Have, A.; van Kan, J.A. The role of ethylene and wound signaling in resistance of tomato to Botrytis cinerea. Plant Physiol. 2002, 129, 1341-1351. [CrossRef]

42. Kaplan, I.; Thaler, J.S. Plant resistance attenuates the consumptive and non-consumptive impacts of predators on prey. Oikos 2010, 119, 1105-1113. [CrossRef]

43. Thaler, J.S. Jasmonate-inducible plant defencedefenses cause increased parasitism of herbivores. Nature 1999, 399, 686. [CrossRef]

44. Brown, E.S.; Dewhurst, C.F. The genus Spodoptera (Lepidoptera, Noctuidae) in Africa and the Near East. Bull. Entomol. Res. 1975, 65, 221-262. [CrossRef]

45. Tian, D.; Tooker, J.; Peiffer, M.; Chung, S.H.; Felton, G.W. Role of trichomes in defense against herbivores: Comparison of herbivore response to woolly and hairless trichome mutants in tomato (Solanum lycopersicum). Planta 2012, 236, 1053-1066. [CrossRef]

46. Díaz, S.; Kattge, J.; Cornelissen, J.H.C.; Wright, I.J.; Lavorel, S.; Dray, S.; Reu, B.; Kleyer, M.; Wirth, C.; Colin Prentice, I.; et al. The global spectrum of plant form and function. Nature 2016, 529, 167-171. [CrossRef] [PubMed]

47. Wright, I.J.; Reich, P.B.; Westoby, M.; Ackerly, D.D.; Baruch, Z.; Bongers, F.; Cavender-Bares, J.; Chapin, T.; Cornelissen, J.H.C.; Diemer, M.; et al. The worldwide leaf economics spectrum. Nature 2004, 428, 821-827. [CrossRef] [PubMed]

48. Escobar-Bravo, R.; Klinkhamer, P.G.L.; Leiss, K.A. Induction of Jasmonic Acid-Associated Defenses by Thrips Alters Host Suitability for Conspecifics and Correlates with Increased Trichome Densities in Tomato. Plant Cell Physiol. 2017, 58, 622-634. [CrossRef] [PubMed]

49. Ataide, L.M.; Pappas, M.L.; Schimmel, B.C.; Lopez-Orenes, A.; Alba, J.M.; Duarte, M.V.; Pallini, A.; Schuurink, R.C.; Kant, M.R. Induced plant-defenses suppress herbivore reproduction but also constrain predation of their offspring. Plant Sci. 2016, 252, 300-310. [CrossRef] [PubMed]

50. R Development Core Team. R: A Language and Environement for Statistical Computing; R Foundation for Statistical Computing: Vienna, Austria, 2018.

51. Torchiano, M. Effsize: Efficient Effect Size Computation, 0.7.4. 2018. Available online: http://github.com/ mtorchiano/effsize/ (accessed on 21 December 2018). 
52. Nakagawa, S.; Cuthill, I.C. Effect size, confidence interval and statistical significance: A practical guide for biologists. Biol. Rev. 2007, 82, 591-605. [CrossRef] [PubMed]

53. Oksanen, J.; Blanchet, F.G.; Kindt, R.; Legendre, P.; Minchin, P.R.; O’Hara, R.B.; Simpson, G.L.; Solymos, P.; Stevens, M.H.H.; Wagner, H. Vegan: Community Ecology Package, 2.0.10. 2013. Available online: http:/ / vegan.r-forge.r-project.org/ (accessed on 4 January 2013).

54. Agrawal, A.A.; Fishbein, M. Plant defense syndromes. Ecology 2006, 87, S132-S149. [CrossRef]

55. Traw, M.B.; Bergelson, J. Interactive Effects of Jasmonic Acid, Salicylic Acid, and Gibberellin on Induction of Trichomes in Arabidopsis. Plant Physiol. 2003, 133, 1367-1375. [CrossRef]

56. Yoshida, Y.; Sano, R.; Wada, T.; Takabayashi, J.; Okada, K. Jasmonic acid control of GLABRA3 links inducible defense and trichome patterning in Arabidopsis. Development 2009, 136, 1039-1048. [CrossRef]

57. Li, L.; Zhao, Y.; McCaig, B.C.; Wingerd, B.A.; Wang, J.; Whalon, M.E.; Pichersky, E.; Howe, G.A. The Tomato Homolog of CORONATINE-INSENSITIVE1 Is Required for the Maternal Control of Seed Maturation, Jasmonate-Signaled Defense Responses, and Glandular Trichome Development. Plant Cell 2004, 16, 126-143. [CrossRef]

58. Boughton, A.J.; Hoover, K.; Felton, G.W. Methyl Jasmonate Application Induces Increased Densities of Glandular Trichomes on Tomato, Lycopersicon esculentum. J. Chem. Ecol. 2005, 31, 2211-2216. [CrossRef]

59. Fine, P.V.A.; Mesones, I.; Coley, P.D. Herbivores Promote Habitat Specialization by Trees in Amazonian Forests. Science 2004, 305, 663-665. [CrossRef] [PubMed]

60. Thaler, J.S. Induced Resistance in Agricultural Crops: Effects of Jasmonic Acid on Herbivory and Yield in Tomato Plants. Environ. Entomol. 1999, 28, 30-37. [CrossRef]

61. Redman, A.M.; Cipollini, D.F., Jr.; Schultz, J.C. Fitness costs of jasmonic acid-induced defense in tomato, Lycopersicon esculentum. Oecologia 2001, 126, 380-385. [CrossRef] [PubMed]

62. Bubici, G.; Carluccio, A.V.; Stavolone, L.; Cillo, F. Prosystemin overexpression induces transcriptional modifications of defense-related and receptor-like kinase genes and reduces the susceptibility to Cucumber mosaic virus and its satellite RNAs in transgenic tomato plants. PLoS ONE 2017, 12, e0171902. [CrossRef] [PubMed]

63. Zhang, H.; Yu, P.; Zhao, J.; Jiang, H.; Wang, H.; Zhu, Y.; Botella, M.A.; Šamaj, J.; Li, C.; Lin, J. Expression of tomato prosystemin gene in Arabidopsis reveals systemic translocation of its mRNA and confers necrotrophic fungal resistance. New Phytol. 2018, 217, 799-812. [CrossRef] [PubMed]

64. Tejeda-Sartorius, M.; Martinez de la Vega, O.; Delano-Frier, J.P. Jasmonic acid influences mycorrhizal colonization in tomato plants by modifying the expression of genes involved in carbohydrate partitioning. Plant Physiol. 2008, 133, 339-353. [CrossRef] [PubMed]

65. Herrera-Medina, M.J.; Tamayo, M.I.; Vierheilig, H.; Ocampo, J.A.; García-Garrido, J.M. The Jasmonic Acid Signalling Pathway Restricts the Development of the Arbuscular Mycorrhizal Association in Tomato. J. Plant Growth Regul. 2008, 27, 221-230. [CrossRef]

66. Leon-Morcillo, R.J.; Angel, J.; Martin, R.; Vierheilig, H.; Ocampo, J.A.; Garcia-Garrido, J.M. Late activation of the 9-oxylipin pathway during arbuscular mycorrhiza formation in tomato and its regulation by jasmonate signalling. J. Exp. Bot. 2012, 63, 3545-3558. [CrossRef] [PubMed]

67. Gutjahr, C.; Siegler, H.; Haga, K.; Iino, M.; Paszkowski, U. Full establishment of arbuscular mycorrhizal symbiosis in rice occurs independently of enzymatic jasmonate biosynthesis. PLoS ONE 2015, 10, e0123422. [CrossRef]

68. Ludwig-Müller, J.; Bennett, R.N.; García-Garrido, J.M.; Piché, Y.; Vierheilig, H. Reduced arbuscular mycorrhizal root colonization in Tropaeolum majus and Carica papaya after jasmonic acid application can not be attributed to increased glucosinolate levels. J. Plant Physiol. 2002, 159, 517-523. [CrossRef]

69. Regvar, M.; Gogala, N.; Zalar, P. Effects of jasmonic acid on mycorrhizal Allium sativum. New Phytol. 1996, 134, 703-707. [CrossRef]

70. Isayenkov, S.; Mrosk, C.; Stenzel, I.; Strack, D.; Hause, B. Suppression of allene oxide cyclase in hairy roots of Medicago truncatula reduces jasmonate levels and the degree of mycorrhization with Glomus intraradices. Plant Physiol. 2005, 139, 1401-1410. [CrossRef] [PubMed]

71. Ligaba, A.; Maron, L.; Shaff, J.; Kochian, L.; Piñeros, M. Maize ZmALMT2 is a root anion transporter that mediates constitutive root malate efflux. Plant Cell Environ. 2012, 35, 1185-1200. [CrossRef] [PubMed]

72. Paszkowski, U. Mutualism and parasitism: The yin and yang of plant symbioses. Curr. Opin. Plant Biol. 2006, 9, 364-370. [CrossRef] [PubMed] 
73. Güimil, S.; Chang, H.-S.; Zhu, T.; Sesma, A.; Osbourn, A.; Roux, C.; Ioannidis, V.; Oakeley, E.J.; Docquier, M.; Descombes, P.; et al. Comparative transcriptomics of rice reveals an ancient pattern of response to microbial colonization. Proc. Natl. Acad. Sci. USA 2005, 102, 8066-8070. [CrossRef] [PubMed]

74. Hause, B.; Mrosk, C.; Isayenkov, S.; Strack, D. Jasmonates in arbuscular mycorrhizal interactions. Phytochemistry 2007, 68, 101-110. [CrossRef] [PubMed]

75. Hause, B.; Schaarschmidt, S. The role of jasmonates in mutualistic symbioses between plants and soil-born microorganisms. Phytochemistry 2009, 70, 1589-1599. [CrossRef] [PubMed]

76. López-Ráez, J.A.; Verhage, A.; Fernández, I.; García, J.M.; Azcón-Aguilar, C.; Flors, V.; Pozo, M.J. Hormonal and transcriptional profiles highlight common and differential host responses to arbuscular mycorrhizal fungi and the regulation of the oxylipin pathway. J. Exp. Bot. 2010, 61, 2589-2601. [CrossRef] [PubMed]

77. Thaler, J.S.; Humphrey, P.T.; Whiteman, N.K. Evolution of jasmonate and salicylate signal crosstalk. Trends Plant Sci. 2012, 17, 260-270. [CrossRef] [PubMed]

78. Werner, G.D.A.; Kiers, E.T. Partner selection in the mycorrhizal mutualism. New Phytol. 2015, 205, 1437-1442. [CrossRef] [PubMed]

79. Kiers, E.T.; van der Heijden, M.G.A. Mutualistic Stability in the Arbuscular Mycorrhizal Symbiosis: Exploring Hypotheses of Evolutionary Cooperation. Ecology 2006, 87, 1627-1636. [CrossRef]

80. Kiers, E.T.; Duhamel, M.; Beesetty, Y.; Mensah, J.A.; Franken, O.; Verbruggen, E.; Fellbaum, C.R.; Kowalchuk, G.A.; Hart, M.M.; Bago, A.; et al. Reciprocal Rewards Stabilize Cooperation in the Mycorrhizal Symbiosis. Science 2011, 333, 880-882. [CrossRef]

81. Fellbaum, C.R.; Mensah, J.A.; Pfeffer, P.E.; Kiers, E.T.; Bücking, H. The role of carbon in fungal nutrient uptake and transport. Plant Signal. Behav. 2012, 7, 1509-1512. [CrossRef]

82. Johnson, N.C.; Graham, J.-H.; Smith, F.A. Functioning of mycorrhizal associations along the mutualism-parasitism continuum. New Phytol. 1997, 135, 575-585. [CrossRef]

83. Roger, A.; GÉTaz, M.; Rasmann, S.; Sanders, I.R. Identity and combinations of arbuscular mycorrhizal fungal isolates influence plant resistance and insect preference. Ecol. Entomol. 2013, 38, 330-338. [CrossRef]

84. Bennett, A.E.; Bever, J.D. Mycorrhizal species differentially alter plant growth and response to herbivory. Ecology 2007, 88, 210-218. [CrossRef]

85. Klironomos, J.N. Variation in plant response to native and exotic arbuscular mycorrhizal fungi. Ecology 2003, 84, 2292-2301. [CrossRef]

86. Vannette, R.L.; Hunter, M.D.; van der Heijden, M. Mycorrhizal abundance affects the expression of plant resistance traits and herbivore performance. J. Ecol. 2013, 101, 1019-1029. [CrossRef]

87. Mathur, S.; Sharma, M.P.; Jajoo, A. Improved photosynthetic efficacy of maize (Zea mays) plants with arbuscular mycorrhizal fungi (AMF) under high temperature stress. J. Photochem. Photobiol. B Biol. 2018, 180, 149-154. [CrossRef]

88. Allen, M.F.; Smith, W.K.; Moore, T.S.; Christensen, M. Comparative Water Relations and Photosynthesis of Mycorrhizal and non-Mycorrhizal Bouteloua gracilis h.b.k. lag ex steud. New Phytol. 1981, 88, 683-693. [CrossRef]

89. Reich, P.B.; Ellsworth, D.S.; Walters, M.B. Leaf structure (specific leaf area) modulates photosynthesis-nitrogen relations: Evidence from within and across species and functional groups. Funct. Ecol. 1998, 12, 948-958. [CrossRef]

90. Reich, P.B.; Walters, M.B.; Ellsworth, D.S. From tropics to tundra: Global convergence in plant functioning. Proc. Natl. Acad. Sci. USA 1997, 94, 13730-13734. [CrossRef] [PubMed]

91. Hartley, S.E.; Gange, A.C. Impacts of plant symbiotic fungi on insect herbivores: Mutualism in a multitrophic context. Annu. Rev. Entomol. 2009, 54, 323-342. [CrossRef] [PubMed]

92. Pineda, A.; Zheng, S.J.; van Loon, J.J.; Pieterse, C.M.; Dicke, M. Helping plants to deal with insects: The role of beneficial soil-borne microbes. Trends Plant Sci. 2010, 15, 507-514. [CrossRef] [PubMed]

93. Martínez-Medina, A.; Fernandez, I.; Lok, G.B.; Pozo, M.J.; Pieterse, C.M.J.; Wees, S.C.M.V. Shifting from priming of salicylic acid- to jasmonic acid-regulated defencedefenses by Trichoderma protects tomato against the root knot nematode Meloidogyne incognita. New Phytol. 2017, 213, 1363-1377. [CrossRef] [PubMed]

94. Cornelissen, J.H.C.; Lavorel, S.; Garnier, E.; Díaz, S.; Buchmann, N.; Gurvich, D.E.; Reich, P.B.; ter Steege, H.; Morgan, H.D.; van der Heijden, M.G.A.; et al. A handbook of protocols for standardised and easy measurement of plant functional traits worldwide. Aust. J. Bot. 2003, 51, 335-380. [CrossRef] 
95. Züst, T.; Rasmann, S.; Agrawal, A.A. Growth-defense tradeoffs for two major anti-herbivore traits of the common milkweed Asclepias syriaca. Oikos 2015, 124, 1404-1415. [CrossRef]

96. Viani, R.A.G.; Rodrigues, R.R.; Dawson, T.E.; Lambers, H.; Oliveira, R.S. Soil pH accounts for differences in species distribution and leaf nutrient concentrations of Brazilian woodland savannah and seasonally dry forest species. Perspect. Plant Ecol. Evol. Syst. 2014, 16, 64-74. [CrossRef]

97. Schädler, M.; Jung, G.; Auge, H.; Brandl, R. Palatability, decomposition and insect herbivory: Patterns in a successional old-field plant community. Oikos 2003, 103, 121-132. [CrossRef]

98. Estrada-Luna, A.A.; Davies, F.T., Jr.; Egilla, J.N. Mycorrhizal fungi enhancement of growth and gas exchange of micropropagated guava plantlets (Psidium guajava L.) during ex vitro acclimatization and plant establishment. Mycorrhiza 2000, 10, 1-8. [CrossRef]

99. Gross, N.; Le Bagousse-Pinguet, Y.; Liancourt, P.; Urcelay, C.; Catherine, R.; Lavorel, S. Trait-mediated effect of arbuscular mycorrhiza on the competitive effect and response of a monopolistic species. Funct. Ecol. 2010, 24, 1122-1132. [CrossRef]

(C) 2019 by the authors. Licensee MDPI, Basel, Switzerland. This article is an open access article distributed under the terms and conditions of the Creative Commons Attribution (CC BY) license (http:/ / creativecommons.org/licenses/by/4.0/). 